\title{
PENGATURAN PENGENDALIAN DAN PENGAWASAN TERHADAP PENJUALAN MINUMAN BERALKOHOL DALAM PERMENDAG NO 6 TAHUN 2015 : STUDI PENERAPAN LESS TRADE RESTRICTIVE WAY DALAM WTO
}

\author{
Oleh \\ Michael Anthony Wirasasmita ${ }^{1}$
}

Abstract

Indonesia as a WTO member country has an obligation to comply with all WTO principles including in the form of less trade-restrictive way. In controlling the sale of alcoholic beverages regulated by Permendag No. 6 of 2015 there is a restriction sale of alcoholic beverages in the micro-and below microenterprise. This regulation based on the WTO Rule has not yet optimally reflected the less trade-restrictive way or the "the most unlikely way to trade". This research uses the normative method. The results show that the control and supervision as mentioned in Permendag No. 6 of 2015 does not fully reflect the WTO Rule and must be changed. Article II Permendag No. 6 of 2015 has revoked the license for the sale of alcoholic beverages for micro-and below microenterprise in order to protect the health and morale of the young generation. This act of control and supervision can still be accomplished in another way so as not to conflict with the spirit of commerce and at the same time still protect the morale and health of the younger generation.

Keywords: Control, Supervision, Alcoholic Beverages.

\begin{abstract}
Abstrak
Indonesia sebagai negara anggota WTO memiliki kewajiban untuk mematuhi semua prinsip WTO termasuk dalam bentuk less trade restrictive way. Dalam pengendalian terhadap penjualan minuman beralkohol yang diatur oleh Permendag No 6 Tahun 2015 terdapat pelarangan penjualan minuman beralkohol yang pada tingkat usaha mikro ke bawah. Pengaturan ini berdasarkan WTO Rule belumlah secara optimal mencerminkan less trade restrictive way atau "cara yang paling tidak bertentangan dengan perdagangan". Penelitian ini menggunakan metode normatif. Hasil penelitian menunjukkan bahwa adapun pengendalian dan pengawasan sebagaimana yang dicantumkan dalam Permendag No 6 Tahun 2015 tidak sepenuhnya mencerminkan WTO Rule dan harus diubah. Pasal II Permendag No 6 tahun 2015 telah mencabut ijin penjualan minuman beralkohol bagi usaha micro ke bawah dengan tujuan untuk melindungi kesehatan dan moral generasi muda. Tindakan pengendalian dan pengawasan ini masih dapat di tempuh dengan cara lain agar tidak bertentangan dengan semangat perdagangan dan juga pada saat yang bersamaan masih dapat melindungi moral dan kesehatan generasi muda.
\end{abstract}

\section{Kata kunci : Pengendalian, Pengawasan, Minuman Beralkohol.}

1 Program Studi Magister (S2) Ilmu Hukum Universitas Udayana, Denpasar, Bali, email: mwwirasasmita@yahoo.com 


\section{PENDAHULUAN}

Perkembangan perdagangan dunia telah mencapai era globalisasi, yang mana masyarakat internasional dalam World Trade Organization telah menuntut liberalisasi dalam setiap aspek perdagangan barang dan jasa. Indonesia sebagai salah satu anggota WTO memiliki tanggung jawab baik secara hukum maupun moral untuk mengimplementasikan semangat perdagangan bebas ini dalam sistem aturan hukum terkait perdagangan di Negara Indonesia.

Trade Liberalization atau lazim dikenal sebagai Perdagangan Bebas, merupakan sebuah upaya untuk membebaskan tindakan pengusahapengusaha asing, untuk masuk dan melakukan perdagangan dalam sektorsektor tertentu negara indonesia. Contoh sektor - sektor yang telah dibuka oleh Pemerintah Indonesia adalah seperti sektor industri makanan, komersial bahan bakar, dan penjualan minuman keras. Perdagangan ini tentunya diatur dalam sebuah Legal Framework Internasional yakni General Agreement On Tarif And Trade 1947 yang telah diadopsi oleh WTO. Aturan ini merupakan landasan internasional yang mengatur khusus tentang perdagangan barang. GATT kemudian digunakan oleh WTO sebagai instrumen untuk melancarkan perdagangan bebas di setiap negara, baik oleh anggota WTO maupun bukan anggota WTO. Adopsi GATT 1994 kedalam WTO dikenal sebagai Annex
1A Multilateral Agreements on Trade in Goods yang mana GATT masuk ke dalamnya.

Jika dalam lingkup internasional terdapat badan yang membidangi perdagangan, secara nasional, Indonesia juga memiliki lembaga khusus membidangi perdagangan, yakni Kementerian Perdagangan. Kementerian Perdagangan adalah kementerian yang mengemban tugas membantu Presiden dalam menyelenggarakan sebagian tugas pemerintah di bidang perdagangan, tugas tersebut mencakup perumusan kebijakan, pelaksanaan, pengawasan, dan penyampaian laporan kepada Presiden terkait bidang perindustrian ${ }^{2}$.

Dalam kata lain, kebijakankebijakan terkait pengaturan mengenai perdagangan bebas secara nasional ini diatur oleh Kementerian Perdagangan. Salah satu kebijakan terbaru yang telah dikeluarkan adalah mulai 16 April 2015, minimarket dilarang berjualan minuman keras alias miras, dan minuman mengandung alkohol hanya boleh dijual di supermarket atau hipermarket dan harus dikonsumsi di lokasi ${ }^{3}$.MenteriPerdagangan(Mendag) Rachmat Gobel mengungkapkan

2 Indonesia.go.id, Kementrian Perdagangan, http://www.indonesia.go.id/in/kementerian/ kementerian/ kementerian-perdagangan/1666profile/182-kementerian-perdagangan, pada 12.58, 20 November 2015.

3 Deutsche Welle, Larangan Berjualan Alkohol di Minimarket Mulai Diberlakukan, http:// www.dw.com/id/ larangan-berjualanalkohol-di-minimarket-mulai-diberlakukan/a18387258, pada 13.12, 20 November 2015. 
"Kita perlu menjaga generasi muda. Dalam era globalisasi kuncinya dari sumber daya manusia (SDM) itu di generasi muda. Kita lihat peta generasi muda di Indonesia seperti apa. Salah satu penyebabnya, karena minuman beralkohol sangat murah sehingga bisa dibeli anak-anak"4. Kecemasan terhadap perkembangan SDM yang berawal dari ancaman akan rusaknya kesehatan generasi muda baik fisik maupun mental merupakan sebuah masalah bagi masyarakat dan pemerintah Indonesia. Seperti yang kita ketahui, terdapat banyak minuman keras yang merupakan hasil export negara lain dalam pasaran nasional, seperti produk Heineken dan Smirnoff yang merupakan produk luar.

Memang dalam salah satu instrumen Annex 1A WTO tentang perdagangan internasional yakni GATT disebutkan bahwa sebuah kegiatan perdagangan dapat dihentikan jika kegiatan tersebut menyebabkan kerusakan pada sektor tertentu, seperti pada Article XX (a) General Exception, "necessary to protect public morals" atau keperluan untuk melindungi moral publik dan (b) "necessary to protect human, animal or plant life or health" atau keperluan untuk melindungi kesehatan manusia, hewan, dan tumbuhan, seperti yang dipaparkan oleh Menteri Perdagangan

4 Lily Rusna Fajriah, Ini Alasan Mendag Larang Minimarket Jual Miras, http://ekbis. sindonews.com/read/990117/34/ini-alasanmendag-larang-minimarket-jual-miras1429167084, pada 13.30, 20 November 2015. yakni ancaman kerusakan terhadap kesehatan fisik atau mental dan moral generasi muda. Akan tetapi penjelasan dalam pasal ini diikuti oleh sebuah cara Less Trade Restrictive Way yang dalam penjelasannya "If this analysis yields a preliminary conclusion that the measure is necessary, this result must be confirmed by comparing the measure with its possible alternatives, whichmaybeless traderestrictive while providing an equivalent contribution to the achievement of the objective pursued $^{5}$ ". Artinya penghentian dari kegiatan perdagangan, seharusnya dilakukan dengan cara yang paling tidak bertentangan dengan kegiatan perdagangan itu sendiri, dalam kata lain jika ada alternatif yang tidak bertentangan maka alternatif itulah yang digunakan.

Terkait hal penghentian penjualan minuman keras ini. Bali merupakan daerah pariwisata internasional, yang mana konsumsi dari minuman keras tersebut sangat menunjang perkembangan ekonomi dan pariwisata Bali. Konsumsi minuman keras ini banyak terjadi dan banyak diperdagangkan secara eceran dan di minimarket, yang justru oleh peraturan menteri tersebut dilarang. Ketika pemerintah melarang adanya penjualan minuman keras dengan alasan melindungi kesehatan publik

5 World Trade Organization, WTO Rules and Environmental Policies: GATT exceptions, https://www.wto.org /english/tratop e/envir e/envt_rules_exceptions_e.htm, pada 13.48 , 20 November 2015. 
dan generasi muda, peraturan tersebut memiliki sudut pandang penyelesaian masalah yang berbeda dengan prinsip cara yang paling tidak bertentangan dengan kegiatan perdagangan. Dengan demikian, isu masalah hukum ini layaklah diangkat ke permukaan agar dapat dibahas lebih lanjut pemecahan masalahnya. Bagaimanakah pengaturan perdagangan minuman keras dalam hukum internasional terhadap hukum nasional di era globalisasi ?

Dalam menunjukkan originalitas penelitian ini, maka akan di tunjukan penelitian sebagai perbandingan. Pertama, Kewenangan Badan Pengawasan Obat Dan Makanan Terhadap Perda Provinsi Bali No 5 Tahun 2012 Tentang Pengendalian Peredaran Minuman Beralkohol ${ }^{6}$. Kedua, Prinsip - Prinsip Eksistensi General Agreement On Tarif And Trade (GATT) Dan World Trade Organization (WTO) Dalam Era Pasar Bebas 7 , Pengaturan Minuman Beralkohol Golongan A Bagi Pelaku Usaha Toko Modern Minimarket ${ }^{8}$.

6 Mahentro, I Putu, Kewenangan Badan Pengawasan Obat Dan Makanan Terhadap Perda Provinsi Bali No 5 Tahun 2012 Tentang Pengendalian Peredaran Minuamn Beralkohol, Jurnal Magister Hukum Universitas Udayana (Udayana Master Law Journal), [S.1.], v. 2, n. 3, nov. 2013. ISSN 2502-3101, Available at: <https://ojs.unud.ac.id/index.php/jmhu/ article/view/7290>. Accessed: 18 sep 2017.

7 Revy S. M. Korah, Prinsp - Prinsip Eksistensi General Agreement On Tarif And Trade (GATT) Dan World Trade Organization (WTO) Dalam Era Pasar Bebas, Jurnal Hukum Unsrat Vol. 22/No.7/Agustus/2016, Available athttps://media.neliti.com/media/ publication/80899-ID-none.pdf, diakses 18 September 2017.

8 A.A. Ngr. Yadnya Wirya R. P dan Gede
Kelebihan artikel ini dibandingkan artikel terdahulu adalah dalam artikel ini akan dimuat lebih spesifik penerapan Permendag No 6 Tahun 2016 yang masih belum secara maksimal menerapkan WTO Rule dalam sektor perdagangan bebas terutama prihal perdagangan minuman beralkohol yang beredar di Negara Indonesia.

$=$ Tujuan penelitian dalam jurnal ini adalah untuk mengatehaui konflik less trade restrictive way yang ada dalam WTO Rule terhadap Permendag No 6 Tahun 2015 tentang Pelarangan Penjualan Minuman Beralkohol.

\section{METODE PENELITIAN}

Metode penelitian yang digunakan dalam penelitian ini adalah Metode Normatif, yang mana Metode Normatif tersebut merupakan penelitian yang menggunakan norma untuk menganalisa inti yang termuat dalam suatu permasalahan. Norma ini kemudian dianalisis dan dibandingkan dengan aturan-aturan hukum yang sedang konflik dan sedang berlaku, guna menemukan pemecahan dari masalah tersebut. Pendekatan penelitian yang digunakan dalam penelitian ini adalah Pendekatan Kasus (the case approach), pendekatan perundang-undangan (the statute

Marhaendra Wija Atmaja, 2015, Pengaturan Minuman Beralkohol Golongan A Bagi Pelaku Usaha Toko Moderen Minimarket, Kerta Semaya, Vol 3 No 5, edisi September 2015,https://ojs.unud.ac.id/index.php/ kerthasemaya/article/view/15300, diakses 23 November 2017. 
approach), pendekatan analisis konsep hukum (analitical \& conseptual approach). Teknik pengambilan data yang digunakan adalah teknik catat dan teknik kepustakaan. Teknik analisis bahan hukum yang digunakan dalam penelitian ini adalah teknik Deskripsi, teknik Evaluasi, dan teknik argumentasi. Jenis data yang akan digunakan adalah media masa atau koran yang merupakan pemberi informasi yang dipilih secara sepesifik untuk memenuhi kebutuhan pemenuhan data penelitian.

\section{HASIL DAN PEMBAHASAN}

Dalam

perdagangan

internasional terdapat banyak faktor yang mempengaruhi keberlangsungan dari kegiatan tersebut. Faktor - faktor seperti kekuatan negara, diplomasi negara , dan keselarasan hukum nasional sebuah negara terhadap hukum internasional. Kekuatan hukum internasional ini ditinjau melalui beberapa teori yang salah satunya adalah pendapat George Jellinek yang mengemukakan bahwa teori kehendak negara merupakan gagasan bahwa kekuatan mengikat hukum internasional terletak pada kehendak negara itu sendiri untuk tunduk pada hukum internasional, karena negara adalah pemegang kedaulatan, maka negara juga merupakan sumber dari segala hukum, dan di dalam teori ini disebutkan bahwa hukum internasional tidak lebih tinggi derajatnya dari pada hukum nasional yang mengatur hubungan luar suatu negara9 . Salah satu sifat hukum internasional adalah bersifat koordinatif atau sejajar, dengan kata lain tidak ada negara yang melebihi atau di atas negara yang lain, dengan demikian sebuah negara dalam masyarakat internasional dapat memilih untuk terlibat dalam sebuah perjanjian atau tidak tanpa adanya paksaan dari negara lain. Sebab adanya perbedaan kekuatan terhadap hukum internasional dan hukum nasional, dalam era globalisasi sangatlah penting jika suasana keselarasan antara hukum internasional dan hukum nasional tercipta.

Keharmonisan hukum merupakan sebuah urgensi dalam penerapan hukum di setiap negara, terutama hukum tersebut merupakan hukum yang mengatur hal yang sangat penting seperti perdagangan barang yang memberikan pengaruh besar dalam perkembangan ekonomi terutama bagi Negara Indonesia. Badan Pembinaan Hukum Nasional Departemen Kehakiman, memberikan pengertian harmonisasi hukum sebagai kegiatan ilmiah untuk menuju proses pengharmonisan hukum tertulis yang mengacu baik pada nilai-nilai filosofis, sosiologis, ekonomis maupun yuridis. Moh. Hasan Wargakusumah dalam Kusnu Goesniadhie S mengemukakan bahwa pengkajian terhadap rancangan

9 Pendidikan Riau, 2013, Hakekat dan Dasar Mengikatnya Hukum Internasional, available from url: https://sospol.pendidikanriau.com 2010/10/hakekat-dan-dasar-meningkatnyahukum.html, pada 13.42, 22 November 2015. 
peraturan perundang-undangan, dalam berbagai aspek telah mencerminkan keselarasan dan kesesuaian dengan peraturan perundang-undangan yang lain, hukum tidak tertulis yang hidup dalam masyarakat, konvensi-konvensi dan perjanjian-perjanjian internasional baik bilateral maupun multilateral yang telah di ratifikasi Indonesia ${ }^{10}$. Kedua teori ini menjadi dasar pelaksanaan hukum internasional terutama dalam perdagangan internasional yang mempengaruhi Indonesia.

Dalam angka 16 bagian mengingat pada Peraturan Menteri Perdagangan (Permendag) Nomor 06/ MDAG/PER/1/2015, dijelaskan bahwa peraturan ini bergerak berdasarkan Peraturan Menteri Perdagangan No.54/M-DAG/10/2009 tentang Ketentuan Umum Bidang Impor. Selanjutnya, Permendag No.54/MDAG/10/2009 juga menjelaskan dalam bagian mengingat bahwa terdapat Undang-Undang No 7 Tahun 2014 tentang Perdagangan dan UndangUndang Nomor 7 Tahun 1994 tentang Pengesahan Agreement Establishing The World Trade Organization (Persetujuan Pembentukan Organisasi Perdagangan Dunia) sebagai salah satu acuan yang penting dalam peraturan terkait barang-barang impor. UU No 7 Tahun 1994 memberikan pengertian

10 Marchyani Wiwiek Dwi , 2010, Harmonisasi Aturan Hukum Buruh Migran Antara International Convention on the Protection of the Rights of All Migrant Workers and Member of Their Families dan UndangUndang Nasional, Surakarta, Universitas Sebelas Maret Surakarta, hlm.27. bahwa Indonesia telah ikut dalam WTO dan telah meratifikasi instrumen -instrumen hukum internasional dalam WTO yang mana GATT merupakan salah satunya. Dengan demikian, adanya hierarki perundang undangan yang menunjukkan bahwa terdapat peraturan hukum yang mengharuskan Indonesia untuk menghormati dan mematuhi prinsip - prinsip yang berada dalam GATT.

Indonesia merupakan negara anggota World Trade Organization yang telah berdiri sejak tahun 1995 . Indonesia memasuki WTO melalui pengesahannya yang tertuang dalam Undang-Undang No 7 Tahun 1994 tentang Pengesahan Agreement Establshing The World Trade Organization(Persetujuan Membentuk Organisasi Perdagangan. Organisasi yang memiliki 161 anggota ini khusus bergerak dalam bidang pengembangan globalisasi perdagangan internasional. Dalam setiap instrumen internasional tentunya terdapat prinsip-prinsip dasar yang digunakan sebagai dasar pembuatan dan pelaksanaan instrumen tersebut. Dalam Annex $1 \mathrm{~A}$ Multilateral Agreements on Trade in Goods : General Agreement On Tarif And Trade 1994 prinsip-prinsip tersebut merupakan prinsip yang mengutamakan keberlangsungan dari kegiatan perdagangan itu sendiri.

Dalam perkembangannya, untuk mempermudah perdagangan barang di dunia, WTO memberlakukan beberapa prinsip utama yang berfungsi sebagai 
aturan dasar guna melindungi kegiatan ekspor impor yang adalah inti dari perdagangan internasional. Prinsip seperti market acces, MFN, dan NT, serta beberapa cara teknis yang digunakan dalam pelaksanaan kegiatan seperti less trade restrictive way, Cara yang paling tidak bertentangan dengan perdagangan atau less trade restrictive way digunakan untuk mendukung market acces guna memberikan keseimbangan dalam menjalankan proses globalisasi perdagangan bagi hampir semua negara di dunia.

Dalam alinea pertama pasal ini dijelaskan bahwa, dalam pelaksanaan General Exception tersebut, haruslah dilaksanakan dengan cara yang tidak diskriminasi dan bukanlah sebuah tindakan terselubung terhadap perdagangan jasa. Lebih lanjut, hal yang dapat menyebabkan adanya pemberhentian ini adalah karena terganggunya moral publik atau stabilitas publik, sebuah keharusan untuk melindungi kesehatan manusia, hewan dan tumbuhan, keharusan pemberhentian karena adanya ketidak selarasan terhadap aturan hukum yang terkait penipuan, privasi individu, dan keselamatan. Dengan terpenuhinya unsur ini, sebuah negara tidak semata - mata bisa menghentikan perdagangan begitu saja. Negara yang menerima eksport barang harus mempertimbangkan prinsip less trade restrictive way yang merupakan prinsip cara yang paling tidak bertentangan terhadap kegiatan perdagangan itu sendiri. Dengan kata lain, prinsip ini memberikan pengertian bahwa jika ada cara lain yang bisa ditempuh untuk memperbaiki atau mencegah kerusakan yang terjadi akibat perdagangan barang, maka cara lain tersebut haruslah di utamakan.

Indonesia meratifikasi GATT pada saat menjadi anggota WTO yang dituangkan dalam Undang-Undang No 7 Tahun 1994 tentang Pengesahan Agreement Establishing The World Trade Organization (Persetujuan Pembentukan Organisasi Perdagangan Dunia). Dengan demikian berdasarkan teori kehendak negara oleh George Jellinek, Indonesia berdasarkan kehendaknya sendiri telah tunduk pada kekuatan hukum internasional yakni Annex 1A GATT. Tindakan ini membawa beberapa pengaruh dari segi hukumdanjugadiplomasi internasional bagi Negara Indonesia terhadap negara lain di dunia. Secara hukum, Indonesia memiliki obligasi untuk mengikuti prosedur - prosedur yang ada untuk menghentikan kegiatan perdagangan. Secara diplomasi, Indonesia harus mempertahankan hubungan antar negara dan reputasi Negara Indonesia terhadap negara investor agar tidak memiliki citra yang buruk dalam masyarakat internasional.

Minuman beralkohol terbagi menjadi 3 (tiga) golongan yakni golongan A yang mengandung etil alkohol dengan kadar sampai dengan 5\% (lima persen), golongan B yang mengandung etil alkohol dengan kadar 
lebih dari 5\% (lima persen) sampai dengan 20\% (dua puluh persen) dan golongan $\mathrm{C}$ yang mengandung etil alkohol dengan kadar lebih dari 20\% (dua puluh persen) sampai dengan 55\% (lima puluhlimapersen) ${ }^{11}$.Perdagangan minuman keras memberikan pengaruh yang signifikan terhadap ekonomi negara. Ketika pemerintah ingin menghentikan penjualan minuman keras tersebut dalam tingkat usaha makro menengah ke bawah, maka secara perlahan tindakan tersebut bersifat menghentikan kegiatan perdagangan ini. Ketika penjualan tersebut dihentikan, investor asing minuman keras akan merasa dirugikan.

Dalam mekanisme perdagangan internasional, ketika pihak investor asing merasa dirugikan, maka investor tersebut dapat nantinya dapat memohon kepada negara asal investor untuk mempermasalahkan regulasi pelarangan minuman keras ini dalam WTO Dispute Settlement. Ketika Panel menemukan bahwa tindakan yang dilakukan oleh pemerintah Indonesia tidak konsisten terhadap Annex $1 A$ GATT. Maka Panel akan meminta negara untuk mengubah atau mencabut aturan tersebut. Apabila pemerintah tidak mengabulkan putusan ini, negara oposisi dapat meminta kuasa "Retaliation" sebagai bentuk pembalasan atas kerugian yang telah dialami akibat pelarangan penjualan

11 Ibid, A.A. Ngr. Yadnya Wirya R. P dan Gede Marhaendra Wija Atmaja. minuman keras ini. Tindakan ini dilakukan ketika sengketa di WTO tidak mencapai resolusi apapun, negara oposisi dapat meminta hak untuk membalas terhadap pelaku ${ }^{12}$, Retaliation dapat dilakukan terhadap produk export Indonesia yang diimpor oleh negara yang dirugikan. Negara oposisi tersebut dapat, nantinya, meningkatkan pajak atau bahkan melarang beberapa produk export Indonesia untuk masuk kedalam negaranya sebagai kompensasi dari ganti rugi yang dialami negara investor. Ketidak konsisten Peraturan Menteri Perdagangan (Permendag) Nomor 06/ MDAG/PER/1/2015 terhadap Annex $1 A$ GATT dapat mengakibatkan sektor lain dalam perdagangan Indonesia mengalami kerugian.

Ketika pemerintahmenggunakan alasan perlindungan publik moral ataupun kesehatan generasi muda sebagai alasan utama dan mendesak untuk diberlakukannya pelarangan penjualan minuman keras, tidak sepenuhnya benar. Masih terdapat cara-cara lain yang dapat digunakan dalam melindungi moral dan kesehatan generasi muda. Sebab adanya pertentangan prinsip dalam Annex $1 A$ GATT dengan Peraturan Menteri Perdagangan (Permendag) Nomor 06/MDAG/PER/1/2015, pemerintah haruslah mencabut larangan penjualan minuman keras

12 Diego Bonomo, Hitting where it hurts: Retaliation requests in the WTO, http://www. voxeu.org/article/retaliation-wto, pada 21.50, 22 November 2015. 
dan memikirkan kembali cara - cara baru untuk melindungi generasi muda tanpa potensi mencederai perdagangan minuman keras. Cara - cara yang memiliki dampak yang lebih ringan atau dampak yang tidak memiliki kemungkinan merusak perdagangan seperti pengendalian melalui bea cukai dan pajak, pengendalian kuantitas dari penjualan minuman beralkohol, dan pengaturan yang tegas akan umur orang yang boleh membeli minuman keras tersebut.

\section{KESIMPULAN}

Perdagangan bebas dalam era globalisasi adalah hal yang penting bagi masyarakat dunia. WTO sebagai organisasi internasional yang bergerak khusus dalam mengembangkan perdagangan bebas tersebut telah mengacu Annex $1 A$ GATT sebagai salah satu instrumen hukum untuk mengatur tata cara perdagangan bebas berlangsung. Indonesia yang telah menjadi anggota WTO dan telah meratifikasi Annex $1 A$ GATT memiliki tanggung jawab untuk mengimplementasikan aturan-aturan yang ada pada Annex $1 A$ GATT dalam hukum nasionalnya. Dengan demikian, segala tindakan yang dilakukan oleh PemerintahIndonesiatidakolehbersifat bersebarangan dengan prinsip - prinsip dalam perdagangan bebas. Permendag Nomor 06/MDAG/PER/1/2015 merupakan salah satu aturan yang tidak sepenuhnya mengoptimalisasi less trade restrictive way dalam $W T O$
Rule yang merupakan prinsip cara yang paling tidak bertentangan terhadap kegiatan perdagangan itu sendiri, sebab masih ada cara - cara lain yang bisa ditempuh jika alasan pelarangan penjualan minuman keras tersebut semata untuk melindungi kesehatan dan moral generasi muda.

\section{DAFTAR PUSTAKA}

\section{BUKU}

Den Bossche, V., Henry, P. L., \& Zdouc, W. (2013). The Law and Policy of the World Trade Organization. Third Edition. Cambridge University Press

Syahuri,D.T.(2010)Konstitusionalitas Regulasi Pembentukan Peraturan Perundang Undangan. Jakarta

\section{ARTIKEL JURNAL}

Mahentoro, I. (2013). KEWENANGAN BADAN PENGAWAS OBAT DAN MAKANAN TERHADAP PERDA PROVINSI BALI NO 5 TAHUN 2012 TENTANG P E N G E N D A L I A N PEREDARAN MINUMAN BERALKOHOL. Jurnal Magister Hukum Udayana (Udayana Master Law Journal), 2(3). doi:10.24843/JMHU.2013. v02.i03.p04.

Korah, R. S. (2016). Prinsip-prinsip Eksistensi General Agreement on Tariffs and Trade (Gatt) 
Dan World Trade Organization (WTO) Dalam Era Pasar Bebas. Jurnal Hukum UNSRAT, 22(7). Yadnya Wirya R. P., A., \& Marhaendra Wija Atmaja, G. (2015). PENGATURAN MINUMAN BERALKOHOL GOLONGAN A BAGI PELAKU USAHA TOKO MODERN MINIMARKET. Kertha Semaya, . Retrieved from https://ojs.unud.ac.id/index.php/ kerthasemaya/article/view/15300.

\section{PERATURAN}

\section{PERUNDANG-UNDANGAN}

General Agreement On Trade And Tarif (GATT)

Undang Undang No 7 Tahun 1994 tentang Pengesahan Agreement Establishing The World Trade Organization (Persetujuan Pembentukan Organisasi Perdagangan Dunia).

Peraturan Menteri Perdagangan (Permendag) Nomor 06/MDAG/ PER/1/2015.

\section{DESERTASI}

Marchyani, W. D. (2010). Harmonisasi aturan hukum buruh migran Antara International Convention on the Protection of the Rights of All Migrant WorkersandMember of Their Families dan UndangUndang Nasional (Doctoral dissertation, Universitas Sebelas Maret).

\section{INTERNET}

Deutsche Welle, Larangan Berjualan Alkohol di Minimarket Mulai Diberlakukan, http://www . dw.com/id/larangan-berjualanalkohol-d i-minimarket mulaidiberlakukan /a-18387258.

Donald Rumokoy, Fungsi Hukum dan Alat Mencapai Tujuan Hukum, http://panduanhukum.com/fungsihukum.

Fokky Fuad, Hukum sebagai Rekayasa Sosial, Kesalahan Pemahaman atas Pemikiran Roscoe Pound, http://uai.ac.id/2011/04/13/ hukum-sebagai-rekayasa-sosialkesalahan-pemahaman-ataspemikiran-roscoe-pound/.

Indonesia.go.id,KementrianPerdagan gan,http://www.indonesia.go.id/ in/kementerian/ kementerian/ kementerian-perdagangan/1666profile/182-kementerian perdagangan.

Lily Rusna Fajriah, Ini Alasan Mendag Larang Minimarket Jual Miras, http://eksis.sindonews. com/read/990117/34/ini-alasanmendag-larang-minimarket-jual-miras1429167084.

Patrick M. Capps, 2009, The Binding Force of International Law. Available fromurl: http://ivrenc.info/index.php?title $=$ The B i n d ing $\mathrm{F}_{-}$r c e of $_{-}$ International Law.

Pendidikan Riau, 2013, Hakekat dan Dasar Mengikatnya Hukum Internasional,availablefromur 
l:http://sospol.pendidikanriau. com/2010/10/hakekat-dandasar-mengikatnya-hukum.html.

World Trade Organization, WTO Rules and Environmental Policies: GATT exceptions, https://www. wto.org/english/tratop_e/envir_ e/envt_rules_exceptions_e.htm Yoga Sukmana, Mulai Besok Minimarket Dilarang Jual Minuman Beralkohol,http:// bisniskeuangan.kompas.com/rea d/2015/04/15/093633626/Mulai. Besok.Minimarket.Dilarang. Jual.Minuman.Beralkohol. 